
Development

\title{
A Capability Approach
}

\section{Thomas Gries ${ }^{1}$ and Wim Naudé}

June 2010

\begin{abstract}
We provide a formal model of entrepreneurship in human development. The framework is provided by the capabilities approach (CA). Hence we extend not only the conceptualisation of entrepreneurship in development, but the reach of the CA into entrepreneurship. From a CA view, entrepreneurship is not only a production factor, or a means to an end, as is often taken to be the case by economists, but also an end in itself. Entrepreneurship can be a human functioning and can contribute towards expanding the set of human capabilities through being both a resource and a process. Our model shows, however, that entrepreneurship is not automatically a functioning. Where it is a necessity it stops being a valued functioning. The model also shows that even when entrepreneurship is valued, entrepreneurs may often not match their ideas with suitable opportunities. Policy implications are discussed.
\end{abstract}

Keywords: capability approach, entrepreneurship, human development

JEL classification: L26, M13,O12, O15

Copyright (C) UNU-WIDER 2010

1 University of Paderborn, Department of Economics, email: thomas.gries@notes.upb.de, ${ }^{2}$ UNU-WIDER, email: Wim@wider.unu.edu

This study has been prepared within the UNU-WIDER project on Entrepreneurship and Development (Promoting Entrepreneurial Capacity), directed by Wim Naudé.

UNU-WIDER gratefully acknowledges the financial contributions to the project by the Finnish Ministry for Foreign Affairs, and the financial contributions to the research programme by the governments of Denmark (Royal Ministry of Foreign Affairs), Finland (Finnish Ministry for Foreign Affairs), Sweden (Swedish International Development Cooperation Agency-Sida) and the United Kingdom (Department for International Development-DFID).

ISSN 1798-7237 ISBN 978-92-9230-306-8 
The World Institute for Development Economics Research (WIDER) was established by the United Nations University (UNU) as its first research and training centre and started work in Helsinki, Finland in 1985. The Institute undertakes applied research and policy analysis on structural changes affecting the developing and transitional economies, provides a forum for the advocacy of policies leading to robust, equitable and environmentally sustainable growth, and promotes capacity strengthening and training in the field of economic and social policy making. Work is carried out by staff researchers and visiting scholars in Helsinki and through networks of collaborating scholars and institutions around the world.

www.wider.unu.edu

$$
\text { publications@wider.unu.edu }
$$

UNU World Institute for Development Economics Research (UNU-WIDER)

Katajanokanlaituri 6 B, 00160 Helsinki, Finland

Typescript prepared by the authors.

The views expressed in this publication are those of the author(s). Publication does not imply endorsement by the Institute or the United Nations University, nor by the programme/project sponsors, of any of the views expressed. 


\section{Introduction}

It is widely believed that entrepreneurship matters for development. In economics, the role of the entrepreneur has been neglected. Moreover, economists have focused on the impact of entrepreneurship on economic output (GDP, productivity, employment) and not so much on human development. Generally the entrepreneur is seen by economists as an innovator, risk-taker and arbitrageur who contributes to economic growth by introducing new technology, competition and markets (Schumpeter, 1911; Kirzner, 1973). As such entrepreneurship is like a production factor. It is even referred to as 'entrepreneurial capital' (Audretsch and Keilbach, 2004; Audretsch, 2007). As a production factor entrepreneurial capital is said to be able to explain the residual typically found in economic growth regressions in two ways. First, entrepreneurs introduce technical change through acting as 'knowledge filters' in the commercialisation of new knowledge (Audretsch et al, 2006). Secondly they improve the allocation of other production factors (Acs and Storey, 2004:873).

Unfortunately, technological innovation, economic growth, and improvements in productivity do not automatically translate into human development. Hence even if entrepreneurship is a determinant of economic growth does not imply that it contributes directly to human development ${ }^{1}$. Until now, however, the literature has neglected the relationship between entrepreneurship and human development. Three potential explanations for this omission are that (i) an adequate theoretical framework for thinking about entrepreneurship in development has been lacking, or not been properly utilised, (ii) the measurement of human development, being multidimensional, is complex and still at the cutting edge of poverty research (see Alkire and Foster, 2008), and (iii) management scholars, who constitute the largest body of researchers into entrepreneurship, are mainly interested in the who, what and how of entrepreneurship, rather than on the impact of entrepreneurship.

The purpose of this paper is to address the lack of an adequate theoretical framework to think about entrepreneurship and human development. We do so by making use of the Capability Approach (CA) to welfare economics, which was pioneered by Amartya Sen and others. Alkire (2002) and Robeyns (2003; 2005) provide useful introductions. The CA has provided the foundation for conceptualising and measuring human development ${ }^{2}$. We believe that the approach is also useful for providing a foundation for modelling entrepreneurship in development.

In the next section, we summarise the CA. Then, in section 3 we derive some implications from the CA for understanding entrepreneurship. In section 4 we

\footnotetext{
${ }^{1}$ Note, however, that the existing empirical literature cannot make an unambiguous case that the level and rate of entrepreneurship are indeed significant determinants of economic growth, productivity or employment. Some studies find a positive relationship, many other no significant or very tenuous relationships at best. Acs and Szerb (2007:109) even report a negative impact of entrepreneurial activity on economic growth in poorer countries. See Naudé (2009) for a more detailed critique of the empirical difficulties faced in estimating the relationship between economic growth and entrepreneurship.

${ }^{2}$ The approach has lead to the compilation of the United Nation's Human Development Index (HDI) published since 1990 by the UNDP as an attempt to provide a multidimensional measure of poverty and well-being.
} 
propose a model wherein human development is, as in the CA, the result of an expansion of the capabilities of economic agents through a better matching of opportunities with entrepreneurial functionings. The final section concludes.

\section{The Capability Approach}

The CA developed from Amartya Sen's criticism of the reliance in welfare economics on incomes and wealth as the only indicators of human development. For Sen, although incomes, wealth and even utility (often measured subjectively by 'happiness') should not be entirely discounted, they cannot fully reflect human development. Human development, according to Sen, is about the expansion of people's positive freedoms (Sen, 2000). These are also described as capabilities. Central concepts in the CA are 'capabilities', 'functionings', 'achieved functionings' and 'agency'. These will now be defined.

Capabilities refer to a person's 'ability to achieve a given functioning'. Functionings are 'valuable activities and states that make up people's well-being' (Alkire,2005:1). Put another way, capabilities are what people are free to do and achieved functionings are 'what they do' (Anand et al., 2009:128). Expanding people's capabilities therefore means expanding their positive choices or 'real freedoms' over functionings. Functionings include (without being exhaustive) 'working, resting, being literate, being healthy, being part of a community, being respected' (Robeyns, 2003:6) ${ }^{3}$. The essence of the CA is to expand people's freedom to choose amongst these functionings those that they value the most $^{4}$ - these can become their achieved functionings if they so choose. According to Robeyns (2003:7) 'What is ultimately important is that people have the freedoms (capabilities) to lead the kind of lives they want to lead, to do what they want to do and be the person they want to be. Once they effectively have these freedoms, they can choose to act on those freedoms in line with their own ideas of the kind of life they want to live.'

Following Anand et al. (2009:128-130) which in turn is based on Sen (1985), we can write the utility $(U)$ that a person derives from a vector of functionings $(f)$ as $U=h(f(g(x))$. This indicates that functionings are made possible by access to resources, which for present purposes may include entrepreneurial capital and opportunities. The function $f$ which maps these to functionings will depend on personal abilities and aspirations as well as the institutional context, as will become clear in the next section. We can now move from functionings to capabilities by defining (following Anand et al., 2009:129) a person's capability set as $Q=\{f(g(x))\}$. This shows that capabilities are determined by the set of functionings from which a person could choose. We will argue that being entrepreneurial is a potential functioning, and that by turning this into an $a c$ tual functioning appropriate policy may contribute to an expansion of people's capability sets. Hence their positive freedoms will increase. As such the CA provides a framework for linking entrepreneurship with human development.

\footnotetext{
${ }^{3}$ Sen does not provide a fixed list of functionings or capabilities.

${ }^{4}$ This has inspired the UNDP's Human Development Report to defined human development 'as a process of enlarging people's choices' (UNDP, 1996:49).
} 
A final concept in CA that we need to refer to here is that of 'agency'. Human development requires that people not be passive recipients or bystanders in their lives but that they have agency. Agency is 'a person's ability to pursue and realize goals that he or she values...the opposite of a person with agency is someone who is forced, oppressed or passive' (Alkire, 2005:3). Without agency entrepreneurship may cease to be a valued functioning.

\section{Entrepreneurship and Human Capabilities}

\subsection{Definition}

In economics, there are two broad and sometimes overlapping approaches towards defining entrepreneurship. The one is behavioural, describing what an entrepreneur does, such as starting a new business, and the other is occupational (or historical), describing an entrepreneur as someone who resorts into some prior defined category such as self-employment or business ownership (Casson, 2003). Within economics entrepreneurship mostly relates to new start-up firms although a number of recent papers have started to note the role of 'institutional' entrepreneurs in social change - although even here institutional entrepreneurs mostly use the firm as a vehicle for affecting change.

For purposes of this paper, and consistent with the economics literature, entrepreneurship can be defined as the resource, process and state of being through and in which individuals utilise positive opportunities in the market by creating and growing new business firms. For instance Shane and Venkataraman (2000) define entrepreneurship as an individual's discovery and exploitation of opportunities and Hart (2003:5) defines entrepreneurship as the 'process of starting and continuing to expand new businesses's. We emphasise positive opportunities here, since many individuals exhibit great initiative and ingenuity in exploiting opportunities for self-gain that are un-productive or even destructive (e.g. Baumol, 1990). Crime, corruption or rent-seeking may pay for the individual materially, but we do not consider such behaviour as enhancing the well-being of either the individual involved nor that of society. As far as the concept of 'opportunities' is concerned, Shane and Venkataraman (2000) define an 'opportunity' as when goods can be sold at a profit. From the perspective of the CA this is inadaquate, because it implies that utility $(U)$ from entrepreneurship depends only on monetary gains. We prefer to see 'opportunities' as when persons can create new firms that will further the kind of lives they desire.

\subsection{Entrepreneurship as Functioning}

Entrepreneurship can be considered a functioning because it relates to how people work. And it can be valued. People can value being entrepreneurial for

\footnotetext{
${ }^{5}$ Many have applied the idea that entrepreneurs exploit opportunities in the firm context to argue that entrepreneurship is in fact part of the management function within existing firms (Hitt et al., 2001) and to coin the term 'intrapreneurship', which is the 'pursuit of creative or new solutions to challenges confronting the firm' (Antoncic and Hisrich 2001:495). We will, however, not be concerned in this paper with 'intrapreneurship'.
} 
various reasons apart from it being a vehicle for material gain. It may provide a sense of achievement, of identity and of being accepted ${ }^{6}$; it may provide independence and it may provide a lifestyle (Moskowitz and Vissing-Jorgensen 2002:747; Licht 2007:825). These non-pecuniary values of entrepreneurship have been well documented. Hamilton (2000) for instance found the non-pecunary value of entrepreneurship to be significant. He found that the median entrepreneur, in business for ten years, could have earned 35 per cent more if he or she had instead chosen wage employment. As he adds (Ibid: 604) 'The differential cannot be explained by the selection of low-ability employees into self-employment and is similar for three alternative measures of self-employment earnings and across industries'. The value attached to entrepreneurship is also evident from high rates of latent entrepreneurship. A 'latent' entrepreneur is someone who is actively seeking an opportunity to be an entrepreneur. Blanchflower et al. (2001) found that in European countries between 27 and 80 per cent of people would like to be entrepreneurs and are looking for opportunities to be so (Ibid: 680).

Although entrepreneurship can be a functioning it should not be assumed that it is always the case. It is perhaps better to describe entrepreneurship as a potential functioning, because there are many instances where being entrepreneurial may not always be valued. In this case the CA provides a perspective that is often overlooked - namely that human development is inconsistent with a situation where people do not value entrepreneurship. Such a situation may exist where people have no choice but to start an own firm because no other labour market option is available. When they are forced to be entrepreneurial, they lose their 'agency'. In this case, being entrepreneurial is not a choice, and may not be fully valued. Here the absence of other functionings and the absence of agency prevents entrepreneurship from being a functioning. For instance having the functionings of being able to work in wage employment or being able to retire due to a pension system ${ }^{7}$ may reduce the need for people to start their own firm. Accordingly the CA provides a fresh perspective on entrepreneurship policies: promoting labour intensity and wage employment, and creating social security are pro-entrepreneurship because they turn entrepreneurship from a potential functioning into an actual functioning ${ }^{8}$. To turn actual functionings into achieved or realised functionings may however require more extensive policy support. It also provides the perspective that policies that aim merely to create a higher rate of new firm start-ups may be welfare-reducing if entrepreneurs do not value it in themselves.

Thus, where supporting functionings or abilities are in place, entrepreneurship can be said to be a (actual) functioning. But it may still not form part

\footnotetext{
${ }^{6}$ See for instance Giannetti and Simonov (2004:269) who find evidence from Sweden that the likelihood of a person being an entrepreneur is higher where there are other entrepreneurs, even if the relative returns to entrepreneurship is lower.

${ }^{7}$ For example in France, where pension benefits are good, the rate of self-employment in the age group 50 to 80 is 5.2 per cent, while for Italy where pension benefits are less good, it is 11.7 per cent (Fonseca et al. 2007:641).

${ }^{8}$ Indirect empirical support for this is provided by Gollin (2008:228) who finds that in more advanced economies, 'the fraction of entrepreneurs should remain fairly flat for countries with per capita income in excess of US\$5,000'.
} 
of people's capability set. People may not have the ability to become entrepreneurial even if they wanted to. They may be constrained in converting their entrepreneurial capital or other resources into starting a new firm. Many latent entrepreneurs in the transition countries of Eastern Europe and the former Soviet Union would want to be entrepreneurial but face significant obstacles in starting their own firms because they lack the abilities to either perceive opportunities or accessing opportunities. This could be due to insufficient entrepreneurial capital, a constraining environment and/or a lack of an enterprising culture (Acs et al, 2008; Estrin et al., 2006).

\subsection{Entrepreneurship as Resource}

In addition to being a potentially valued functioning, entrepreneurship is also a resource. Entrepreneurial abilities, attitudes and aspirations are important prerequisites for being entrepreneurial. These differ across countries and seem to be related to achieved rates of new firm start-ups (Acs and Szerb, 2009). Entrepreneurship is a resource because entrepreneurial behaviour often creates wage employment for others as well as opens up other functionings - i.e. what may be for one person an intrinsic good, may be for another a means to an end. In this sense it does act as 'entrepreneurial capital' which can be translated into a new business firm or employment for others. It can also be translated into other functionings such as being in better health, having better education, enjoying greater peace and security ${ }^{9}$. The fact that these outcomes differ across countries that seem to have similar rates of entrepreneurial capital point to the fact that not all societies are equally adapt and translating entrepreneurial capital into valuable functionings. More research is needed to understand this relationship better.

\subsection{Agency and Entrepreneurship}

The concept of agency was mentioned as being central in the CA. It was also pointed out that people lack the agency to be entrepreneurial when they are forced to start their own firms. Agency in respect to entrepreneurship also relates to entrepreneurial orientation and ability in the sense in which it allows an entrepreneur to spot an opportunity and to utilise it. It refers to the entrepreneur's locus of control, self-efficiency, confidence and ability. Very often circumstances in a country or region inhibits human entrepreneurial agency, not only by excluding the options for wage employment as already discussed. It also inhibit agency through the effects of the environment on people's self-confidence and self-esteeem, and through the effects of deprivation on the inclination, motivation and time people spend looking for opportunities. For instance, it has been found that females tend to be less active in new firm start-ups than men. One reason is due to the inhibiting of their agency, through for instance cultural norms, beliefs or outright discrimination which lowers women's self-confidence

\footnotetext{
${ }^{9}$ The fact that entrepreneurship is both a means to an end as well as an end in itself is typical of many capabilities. Robeyn (2005:95) mention the case of being healthy, which is valued in itself, but which also allows the means to work.
} 
(see Minniti and Naudé, 2010). Furthermore many people lack the inclination, motivation and even time to be searching for opportunities. Banerjee and Duflo (2007:165) are perplexed by the apparent lack of the poor to perceive opportunities, stating 'one senses a reluctance of poor people to commit themselves psychologically to a project of making more money'. This may, however, not only reflect a lack of psychological commitment, but also that entrepreneurs have limited attention, and that in poor countries the environment is such that it attaches a very high cost for an individual to turn attention away from pressing matters in order to seek or perceive new opportunities-which may be scarce (Gifford 1998:17). For many persons at subsistence level it is a high risk to try and exploit opportunities which are subject to uncertainty. The concept of agency allows a further fresh insight into the entrepreneurship policies as it suggests that the promotion of gender equality, and of encouraging people's self-confidence, locus of control, self-esteem and motivation to search for opportunities are important requirements (even complementary functionings) to being entrepreneurial.

\section{A Model of Entrepreneurship and Human De- velopment}

In this section we formalise the ideas from the previous section by proposing a simple model wherein the expansion of people's capability to utilise positive opportunities are consistent with human development.

\subsection{Entrepreneurs and Opportunities}

In our model the total number of potential entrepreneurs is exogenous at level $E$. At any given moment, there will be a number of latent entrepreneurs which we denote by $u$ and a number of active entrepreneurs, denoted by $n$. The allocation of the total entrepreneurial potential in the economy is therefore $E=n+u$.

We treat opportunities as distinctly separate from individuals. Some in the literature would disagree with this view. McMullen et al. (2007:3) for instance believe that 'the subjective or socially constructed nature of opportunity makes it impossible to separate opportunity from the individual'. However, given the CA's caution against relying too much on subjective evaluations of well-being, it offers a potentially fresh way of looking at opportunities in the field of entrepreneurship. For instance, is inadequate human development partly the outcome of insufficient 'opportunities tied to activities that yield economic growth' (Coyne and Leeson, 2004:236)? Or does economic growth create opportunities which could yield improvements in human development? If the answers to both of these questions are positive, it would mean that opportunities can indeed be treated as separate from individuals.

We denote the total number of potential opportunities for new firm start-ups by $\Omega$. We assume that these opportunities are rivalrous and excludable, so that each opportunity can only be utilised by a single entrepreneur. At any time $t$, there are three types of start-up opportunities. 
First, there are the taken opportunities $(n)$. These are the opportunities that have already been transformed into a business firm. In the terminology of the $\mathrm{CA}$ these may be interpreted as achieved functionings. We recognise that these taken opportunies are subject to uncertainty so that people do not automatically have the capability of entrepreneurship.

Second, there are the opportunities that have not yet been taken $(\omega)$ even if they are presently profitable and could contribute to functioning - we call these untaken or open opportunities. We see these oppportunities as positive opportunities. In taking these, entrepreneurs will not only contribute to their own welfare, but they would not adverse impact on anybody else's. In future extensions of the model relaxing this assumption may allow the possibility to model destructive entrepreneurship.

Third, there are opportunities that could be taken, but would not provide the entrepreneur with any value. These are opportunities where entrepreneurship ceases to be a functioning - it is not valued. We call these idle opportunities and denote them by $\delta$. The utilisation of idle opportunities may be interpreted as necessity or survival strategies when no alternative incomes outside the labour market are available. In more advanced economies, where social transfer programmes are available, persons may not be forced to take up such idle opportunities. In the terminology of the previous section idle opportunities reflect entrepreneurial activity in the absence of agency.

Given the three types of opportunities we can write the total number of opportunities in the economy as $\Omega=n+\omega+\delta$. In the next section we model the process by which open and idle opportunities are recognised and converted into business firms.

\subsection{New Firm Start-Ups as a Match}

If a latent entrepreneur spots an open opportunity, a new firm can be started up. A start-up therefore implies a match - more specifically a match between the particular opportunity and the nature (ability, vision, apsirations and business plan) of the latent entrepreneur ${ }^{10}$. The number of new start-up firms per period, the start-up rate, is denoted $\mathcal{M}=\mu M$. An aggregate matching process $M$ can be modelled by a matching technology which indicates that the number of successful matches is positively determined by the number of open opportunities $(\omega)$, the number of latent entrepreneurs $(u)$, and the latent entrepreneur's effort or intensity of searching $\nu$.

The start-up rate therefore can be written as $\mathcal{M}=\mu M(\omega, u, \nu)$, where $M_{\omega}>0, M_{u}>0, M_{\nu}>0 .{ }^{11}$ Here the parameter $\mu$ provides an indicator of the overall efficiency with which latent entrepreneurs and open market opportunities are matched. In terms of the capability approach, $\mu$ is an indicator of the extent to which resources in the economy can be translated into entrepreneurship. It will depend on the features of the external economy, such

\footnotetext{
${ }^{10}$ Grégoire and Shepherd (2005) stress potential entrepreneurs' cognitive abilities as crucial in this regard and Shane (2000) stresses the role of entrepreneurs' prior knowledge and experience.

${ }^{11}$ The model is a modified version of the labour market matching appraoch as introduced by Pissarides (2000).
} 
as for instance the institutional framework. But the successful matching of latent entrepreneurs and opportunities may also depend on characteristics of the entrepreneur. Therefore, we have a second matching-efficiency parameter in $\nu$. Here $\nu$ indicates the efficiency with which latent entrepreneurs search for opportunities. Total entrepreneurial search activities in efficiency units are described by $\nu u$. Later we will illustrate how improvements in the efficiency with which entrepreneurs search for opportunities, and the efficiency of the institutional framework within which they search, will result in an increase in the rate of new firm start-ups. The matching process can be written as a simple linear homogeneous matching function of the type

$$
\mathcal{M}=\mu M(\omega, u, \nu)=\mu \omega^{\beta}(\nu u)^{1-\beta}
$$

where $\beta$ is the elasticity of additional open opportunities on matching, and hence successful start-ups, and $1-\beta$ is the elasticity of increasing aggregate total search efforts on start-ups ${ }^{12}$. From the perspective of a representative latent entrepreneur the probability of a match is $\mu m=\mu M / u$.

\subsection{Agency and Search Effort}

The concept of agency is central in the CA as was explained in section 2. People are not passive recipients of the outcomes in their lives, but want to and can steer these outcomes. The degree to which they can determine their agency. With agency people may feel that entrepreneurial opportunities are valuable, motivating their search for opportunities. The latent entrepreneur $i$ will then have to decide upon his or hers search effort.

We denote the search effort by $\eta_{i}$. While higher search effort increases his or hers search efficiency, $\nu_{i}\left(\eta_{i}\right)$, and hence the probability of starting a new firm $\left(\mu m_{i}\right)$, search effort is subject to search costs $c_{i}\left(\eta_{i}\right)$. By introducing search costs we take into account that valuing entrepreneurship as a functioning has an opportunity cost. For simplicity both functions are assumed to be linear with a marginal effort efficiency $\bar{\nu}_{i}$, and marginal search costs per unit of search efficiency $\bar{c}_{i}$. In this rather rudimental approach the search efficiency and search cost functions allow us to identify the impact of the broader economic and institutional environment on the degree to which entrepreneurship turns out to be a functioning. For instance, if $\bar{\nu}_{i}$ is high, little effort is needed to increase search efficiency. It is easy to think of reasons for a high $\bar{\nu}_{i}$. For example entrepreneurial ability, experience, aspirations are all characteristics of entrepreneurship (as a resource) that will raise the efficiency $\bar{\nu}_{i}$.

Search $\operatorname{cost} c_{i}$ indicate how easy it is to obtain a certain level of search efficiency. If $\bar{c}_{i}$ is high the resource and opportunity costs connected with active search and start-up activities are high. This may reflect high information and transaction costs inherent in the general business and institutional environment. The latter may for instance be characterised by a number of obstacles to business start-ups, such as high start-up costs, high regulatory burdens, high

\footnotetext{
${ }^{12}$ As long as the matching process is assumed linear homogeneous the value of $\beta$ also describes the relative importance of open opportunities compared to search efforts for successful matching.
} 
taxation, difficulties of doing business, and a lack of physical or informational infrastructure. Within the CA it is important to take the resource and opportunity costs of searching into consideration, as it influences people's choices from amongst their capability set. Many choices may appear to be in the capability set $Q$, but may in fact be precluded as a result of their high cost.

\subsection{Occupational Choice}

Because searching for opportunities is costly, but also offers the promise of potential rewards, the extent of an individual's search effort can now be modelled as the outcome of an optimisation exercise.

At any moment in time a person has to choose to be either an active entrepreneur, or to be in non-entrepreneurial occupations. Both can be a functioning; however, for entrepreneurship to be valued will depend on whether a person is able to take an open opportunity or whether he or she is forced into self-employment - here taking on an idle opportunity with low or even no functioning. For each of these possibilities we will derive the expected benefits of making an occupational choice to determine the optimal search effort.

1. The value of remaining in non-entrepreneurial activities: ${ }^{13}$ The (functioning) value of a latent entrepreneur currently in non-entrepreneurial activities $W_{i}$ can be described by two components.

The first component of total functioning value of the non-entrepreneurial state is the value of the pure non-entrepreneurial occupation. Non-entrepreneurial occupations are wage-employment, self-employment or unemployment. In developing economies these occupations may be unstable. In each period a person may have a wage-employment income $y_{i}^{w}$ with probability $\alpha_{i}^{w}$, or may earn some income from forced self-employment $y_{i}^{s}$ (taking an idle opportunity) with probabillity $\alpha_{i}^{s}$, or he/she may even have no job, recieving only a subsistence transfer income $y_{i}^{\tau}$. Due to the high instability of non-entrepreneurial occupations the exogenously given probability vector $\alpha_{i}$ and income vector $y_{i}$ contribute to the expected functioning of the state of not being an entrepreneur. Hence, each period's value of functioning of this state of occupation is $w_{i}=h\left(f\left(\alpha_{i}, y_{i}\right)\right)$. The total functioning value of the non-entrepreneurial occupation is the expected net present value of each period's values $w_{i}$ minus search opportunity $\operatorname{costs} c_{i}$, adjusted for the probability of remaining in the non-entrepreneurial state of occupation $1-\mu m_{i}$. For a given time preference rate $\rho$ and in continuous time this value is $\int_{0}^{\infty}\left(w_{i}-c_{i}\right) e^{-\left(\rho+\mu m_{i}\right) t} d t$.

The second component of the total functioning value of the non-entrepreneurial state is the value of a potential switch. At any given time the latent entrepreneur can switch from wage employment to being an active entrepreneur. Therefore, in each period there is the probability $\mu m_{i}$ of starting up a new firm. The expected value from switching to being an active entrepreneur is denoted by $V_{i}{ }^{14}$ In continuous time the value of this second component is $\int_{0}^{\infty} \mu m_{i} V_{i} e^{-(\rho+\mu m) t} d t$.

\footnotetext{
${ }^{13}$ Note that we look at an exisiting state of presently being in non-entrepreneurial occupations in period $t=0$.

${ }^{14}$ Note that $V_{i}$ is an expected value including all potential paths of switching into and out of entrepreneurial activities after a first start-up.
} 
The total expected present value of remaining as a latent entrepreneur is $W_{i}=\int_{0}^{\infty}\left[w_{i}-c_{i}+\mu m_{i} V_{i}\right] e^{-\left(\rho+\mu m_{i}\right) t} d t$, and hence

$$
W_{i}=\frac{1}{\rho}\left[w_{i}-c_{i}+\mu m_{i}\left(V_{i}-W_{i}\right)\right]
$$

Because the latent entrepreneur could switch to become an active entrepreneur, the functioning value $V_{i}$ of being an active entrepreneur also needs to be considered.

2. The value of being an active entrepreneur: The (functioning) value of being an active entrepreneur $V_{i}$ can also be described by two components.

The first component is the value of the pure entrepreneurial occupation. This is given by the expected net present value of each period's entrepreneurial functioning values $v_{i}$, adjusted for the probability $1-\phi_{i}$ of remaing an active entrepreneur (not failing in business and switching back into non-entrepreneurial occupation with probability $\phi_{i}$ ). For a given time preference rate $\rho$ and in continuous time this value is $\int_{0}^{\infty} v_{i} e^{-\left(\rho+\phi_{i}\right) t} d t$.

The second component of the total functioning value of the entrepreneurial state is the value of the potential switch into non-entrepreneurial occupation. This will be determined by the fact that in each period the entrepreneur faces the probability $\phi_{i}$ that his or her firm may fail. On switching, the expected value of being in a non-entrepreneurial occupation is $W_{i}$. In continuous time the value of this second component is $\int_{0}^{\infty} \phi_{i} W_{i} e^{-\left(\rho+\phi_{i}\right) t} d t$

The total expected present value of being an active entrepreneur is $V_{i}=$ $\int_{0}^{\infty}\left[v_{i}+\phi_{i} W_{i}\right] e^{-\left(\rho+\phi_{i}\right) t} d t$ and hence ${ }^{15}$

$$
V_{i}=\frac{1}{\rho}\left[v_{i}-\phi_{i}\left(V_{i}-W_{i}\right)\right]
$$

It follows that once the value of remaining in the non-entrepreneurial state and the value of being an active entrepreneur are determined, the latent entrepreneur will choose the optimal level of search effort so as to maximise the expected total value - or the value of work functioning, which is part of the capability set of the individual. Determining the optimal effort, the latent entrepreneur can now improve the chance to become an entrepreneur in an optimal way by $^{16}$

$$
\max _{\eta_{i}}: \rho W_{i}=\left[w_{i}-c_{i}+\mu m_{i}\left(\nu_{i}\left(\eta_{i}\right)\right) \Delta_{i}\right]
$$

were $\Delta_{i}$ is the expected additional total net value of being an entrepreneur instead of ramaining in the non-entrepreneurial state $\left(\Delta_{i}=V_{i}-W_{i}\right)$. However, this is only if the latent entrepreneur wants to become an active entrepreneur. Hence, what this shows is that the search intensity of each latent entrepreneur depends on the extent to which entrepreneurship is valued as a functioning.

\footnotetext{
${ }^{15}$ See for an analog discussion with respect to labour market matching theory Pissarides $(2000)$.

${ }^{16}$ See for an analog discussion with respect to labour market matching theory Pissarides (2000 ch. 5).
} 
Proposition 1: For given $\bar{c}_{i}>0, \bar{\nu}_{i}>0, \mu>0$, and a linear homogeneous matching function $M$ we obtain an optimal effort for realising the entrepreneurial vision $\eta_{i}^{*}$ as function of $x=\left(\omega, u, \Delta_{i}, \bar{c}_{i}, \bar{\nu}_{i}, \mu\right)$,

$$
\begin{aligned}
\eta_{i}^{*} & =\eta_{i}^{*}(x) \\
\eta_{i \Delta_{i}}^{*} & >0, \quad \eta_{i \omega_{i}}^{*}>0, \quad \eta_{i u_{i}}^{*}<0, \quad \eta_{i \bar{c}_{i}}^{*}<0, \quad \eta_{i \bar{\nu}_{i}}^{*}>0, \quad \eta_{i \mu}^{*}>0
\end{aligned}
$$

For a proof see Appendix 1.

\subsection{Aggregate Matching with Individual Decision}

In order to determine the stationary equilibrium outcome we now have to turn to the aggregate level of the economy.

Value differential: Assuming representative individuals we can consider the aggregate level of difference in the values of either being non-entrepreneurial or entrepreneurial $\Delta$. Using (1) and (2) we can write

$$
\Delta[\rho+\phi+\mu m]=v-w+c .
$$

Stationary matching: On the aggregate level of the economy the stationary equilibrium outcome needs to be determined. With the number of failed business opportunities given by $\phi n$ and the number of matched start-up opportunities by $\mu M$, the dynamics of business activity (churning) in the economy is $\dot{n}=\mu M-s n$. The associated stationary flow equilibrium condition is

$$
\dot{n}=0, \quad \mu M=\phi n .
$$

Open opportunities: To determine the equilibrium number of successful new firm start-ups, the dynamics of opportunities must be described. We assume that these dynamics are captured by two probabilities denoted $p$ and $q$. Here $p$ is the given probability that formerly profitable opportunities - either taken or still open - become unprofitable idle opportunities. And $q$ is the given probability that formerly idle opportunities become profitable again. The probabilities may be determined by exogenous forces such as institutional changes. If the economy for instance becomes less stable, $p$ is likely to rise. It could be the result of structural change, growth or other characteristics connected to the economy's state of development. Likewise $q$ indicates a general improvement in transition from the state of self-employment towards entrepreneurship. Thus the change in idle opportunities is given by $\dot{\delta}=p(\omega+n)-q \delta$ and the associated stationary flow equilibrium for opportunities can be described as

$$
\dot{\delta}=0, \quad \omega=\frac{q}{p+q} \Omega-E+u
$$

where we made use of the definition of $\Omega$ from above to substitute for $\delta$. As we assume that there are sufficient opportunities compared to potential entrepreneurs $\frac{q}{p+q} \Omega-E>0$ there are always more open opportunities than latent entrepreneurs $\omega>u$.

With equation (4), (5) and (6) we obtain a system of three equations with three endogenous variables $(\omega, u, \Delta)$ to solve for. The system is determined 


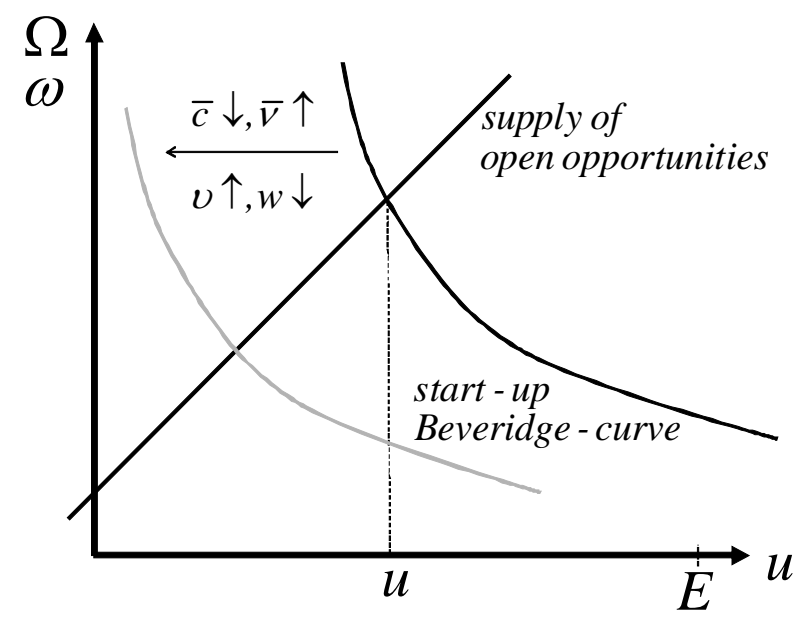

Figure 1: Start-up Beveridge Curve

by information costs and market conditions described by the overall matching efficiency $\mu$, the expected entrepreneurial flow value of functioning search costs $\bar{c}$, effort efficiency $\bar{\nu}$, the entrepreneurial and non-entrepreneurial functioning values $v_{i}$ and $w_{i}$, and the general entrepreneurial environment as reflected in the ability of the market to absorb new product variations $\Omega$, the stability of market conditons identified by $p$ and $q$, and the entrepreneurial capacity/potential of the economy $E$.

$$
\begin{array}{rlc}
0 & =\phi(E-u)-\mu M(\omega, u, \nu(\eta(x))) & \text { (stationary matching) } \\
0 & =\Delta\left(\rho+\phi+\mu \frac{M}{u}(\omega, u, \nu(\eta(x)))\right)-v+w-c(\nu(\eta(x))) \text { (value diff.)(7) } \\
0 & =\omega-\frac{q}{p+q} \Omega+E-u & \text { (supply of open opportunities) }
\end{array}
$$

Proposition 2: Using the implicit function theorem, we can solve for a vector $\left(u^{*}, \omega^{*}, \Delta^{*}\right)$ as functions of the vector of exogenous variables $z=$ $(\mu, \bar{c}, \bar{\nu}, q, p, \Omega, E, v, w)$

$$
u^{*}=u^{*}(z), \quad \omega^{*}=\omega^{*}(z), \quad \Delta^{*}=\Delta^{*}(z)
$$

For a proof see Appendix 2.

We can now show that, consistent with the capabilities approach, human development is associated with a higher degree of entrepreneurial functioning in an economy. In particular, we can conclude that as long as the value of 
entrepreneurial functioning of latent entrepreneurs exceeds the value of nonentrepreneurial functioning, the overall degree of functioning in the economy improves with the share of active entrepreneurs out of all potential entrepreneurs

$$
\Phi=\frac{n}{E}=1-\frac{u}{E}
$$

Hence $\Phi$ indicates an overall degree of functioning from entrepreneurial activities. For illustrative purposes we can draw a start-up Beveridge-curve ${ }^{17}$ and the open opportunities-curve in Figure 1. Analog to the labour market Beveridgecurve the start-up Beveridge-curve summarises the relation of open opportunities to latent entrepreneurs. The closer the start-up Beveridge-curve is to the origin the more efficient are market conditons with respect to transaction and information costs, market institutions and the general business environment.

\section{Institutions and Appraisal of Entrepreneur- ship}

Having set out a model of entrepreneurship from the perspective of the CA we will now illustrate how the model relates development policy to entrepreneurship. We focus on the role of institutions and the value of entrepreneurship as a functioning.

\section{$5.1 \quad$ Institutions}

In the previous section we pointed out that the general economic and institutional environment is important in determining how individuals allocate their occupational decisions between entrepreneurial and non-entrepreneurial activities. The broad general and institutional environment in the present model influences the efficiency of entrepreneurs' search efforts, and information and transaction costs. If these improve, we expect to see an increase in the overall degree of entrepreneurship as functioning, and hence in the start-up rate of new firms. Formally,

Proposition 3: For $\frac{q}{p+q} \Omega-E>0$ improvements in the efficiency with which entrepreneurs search for opportunities $\bar{\nu}$, and lower information and transaction costs $\bar{c}$, will lead to an increase in the rate of new firm start-ups and improve the degree of functioning from entrepreneurial activities $\Phi$.

$$
\begin{aligned}
\frac{d \Phi}{d \bar{c}} & =\frac{(\rho+\phi+\mu m) \frac{\nu u}{\Delta \beta}}{\mu^{2} M(1-\beta) m\left(\frac{1}{\omega}-\frac{1}{u}\right)-(\rho+\phi+\mu m)\left(\mu \frac{M}{\omega}+\phi\right)}<0 \\
\frac{d \Phi}{d \bar{\nu}} & =\frac{-(\rho+\phi+\mu m) \mu \frac{(1-\beta)^{2}}{\beta} M}{\mu^{2} M(1-\beta) m\left(\frac{1}{\omega}-\frac{1}{u}\right)-(\rho+\phi+\mu m)\left(\mu \frac{M}{\omega}+\phi\right)}>0
\end{aligned}
$$

${ }^{17}$ The start-up Beveridge-curve can be derived from the first two equations of the system (7). The start-up Beveridge-curve is in analogy to the labour market Beveridge-curve. 
For a proof: see Appendix 3.

In Figure 1 improvements in search efficiency and lower information and transaction costs, due to institutional strenghtening, will shift the start-up Beveridge-curve downward - showing a reduction in the number of latent entrepreneurs and a rise in the number of active entrepreneurs.

\subsection{Value of Entrepreneurial Activities}

We can also illustrate the model by focusing on the valuation of other occupations relative to entrepreneurship. When the functioning value of other occupations, including forced self-employment and wage employment decline, latent entrepreneurs' search intensity may increase. Similarly, in an environment where entrepreneurship generates a high functioning compared to other occupations, search intensity will increase. Search intensity is therefore an important indicator of the relative value attached to entrepreneurship ${ }^{18}$.

Proposition 4: For $\frac{q}{p+q} \Omega-E>0$ functioning from entrepreneurial activities $\Phi$ is positively related to the degree to which entrepreneurship and other occupations are being valued as a functioning [indicated by $v$ and $w$ ].

$$
\begin{aligned}
& \frac{d \Phi}{d v}=\frac{-\mu(1-\beta) \frac{M}{\Delta \beta}}{\mu^{2} M(1-\beta) m\left(\frac{1}{\omega}-\frac{1}{u}\right)-(\rho+\phi+\mu m)\left(\mu \frac{M}{\omega}+\phi\right)}>0 \\
& \frac{d \Phi}{d w}=\frac{\mu(1-\beta) \frac{M}{\Delta \beta}}{\mu^{2} M(1-\beta) m\left(\frac{1}{\omega}-\frac{1}{u}\right)-(\rho+\phi+\mu m)\left(\mu \frac{M}{\omega}+\phi\right)}<0
\end{aligned}
$$

For a proof see Appendix 4.

This result makes clear that when people have little choice, or where few opportunities for profitable and rewarding small business activities exist, that they will reduce their search intensity. If opportunities and potential entrepreneurial activities are not expected to provide sufficient functioning the motivation to become an entrepreneur is low and entrepreneurship, even if possible, has little to contribute to individual welfare. This is consistent with empirical evidence from poor countries. As we have remarked in section 3, researchers have often been perplexed by the lack of interest by poor self-employed people to look for more profitable business opportunities (Banerjee and Duflo, 2007; Gifford, 1998). QED.

\footnotetext{
${ }^{18}$ Little effort has been made in the empirical entrepreneurship literature to measure the search intensity of latenty entrepreneurs. Given its importance in understanding the functioning value of entrepreneurship, our model suggest that this is a shortcoming, and that indicators for measuring the contribution of entrepreneurship to development ought in future attempt to measure this aspect.
} 


\section{Concluding Remarks}

In this paper we argued that the CA provides a useful point of departure to formalise the roles of entrepreneurship in human development. We have argued that entrepreneurship is both a resource and a process, so that it contributes towards expanding other human capabilities and means, such as providing the ability to work, to earn incomes, and to accumulate wealth. But being entrepreneurial can also in itself be a valued human functioning. We illustrated that this valuation of entrepreneurship as a choice, depend on whether people have agency. Where entrepreneurship is a necessity or is forced is ceases to be a valued functioning. This can often be the case where people cannot access formal wage employment (perhaps due to insufficient skills, or lack of employment opportunities) or where their efforts to start-up a new firm of their choice is obstructed. Thus, the value of entrepreneurship would be reflected in whether people have the choice not to be an entrepreneur.

For entrepreneurship policies to be consistent with human development will require these policies to increase the value attached to entrepreneurship as functioning. The theoretical model we proposed in this paper illustrated that the extent to which (latent) entrepreneurs will be searching for a new opportunity to start a firm, is an indicator of the extent to which entrepreneurship is valued. This is consistent with empirical findings which suggest that in developed countries the extent of latent entrepreneurship is much higher than in less developed countries. The model also showed that even when entrepreneurship is valued, entrepreneurs may often not match their ideas with a suitable opportunity, due to transactions and information costs, and other obstacles in the business environment. These are often said to be the result of a poor institutional and regulatory framework. Hence, a policy implication from our model is inter alia that policies to reduce transactions and information costs and facilitate search intensity, for instance by reducing search costs, are consistent with human development.

So far, these policy recommendations are in line with the standard set of entrepreneurship policy perscriptions. However, where our policy recommendations differ from most entrepreneurship promotion policies, are in the following. First, with entrepreneurship being a valued functioning, and not just having instrumental value (or being a derived demand as some term it) entrepreneurship policies that require firm growth or profitability as sole or the most important indicators of success are likely to be misplaced. Second, policies to create higher levels of entrepreneurial awareness of aspirations (for instance central in the European Commission's approach) will in themselves not be successful unless search costs are also reduced. Third, if entrepreneurship is a resource that contributes to other valued functionings, then building entrepreneurship as resource should also be a policy objective - through for instance policies that promote economic growth and hence the range of business opportunities available. The causality between economic growth and entrepreneurship thus could run as much from the former to the latter as the other way around. And finally, entrepreneurship will not always be valued, especially if people lack agency. Thus policies that increases people's process freedoms, but also their alternatives to 
being entrepreneurial, such as wage employment, will be promoting human development. Measuring (latent) entrepreneurs' search intensity may provide a useful indicator within a set of multidimensional well-being indicators.

The model proposed in this paper has shown that the CA offers a useful framework from where to approach the contribution of entrepreneurship to human development. It is, however, a rather simple model and does not claim to be able to fully capture or model the CA. Nevertheless, we hope it has illustrated the cross-disciplinary applicability of the CA and will encourage others to further explore the richness and validity of this approach to both human development and entrepreneurship.

\section{Appendices}

\subsection{Appendix 1: Proof of Proposition 1}

Proof of proposition 1: From the F.O.C. we obtain:

$$
-\bar{c}_{i}+\mu \frac{M_{\nu}}{u} \bar{\nu}_{i} \Delta_{i}=0 .
$$

Since $M$ is a linear homogeneous function we can apply the implicit function theorem to determine $\eta_{i}^{*}$ being an implicit function $x$

$$
\eta_{i}^{*}=\eta_{i}^{*}(x),
$$

with $x=\left(\omega, u, \Delta_{i}, \bar{c}_{i}, \bar{\nu}_{i}, \mu\right)$ and the derivatives

$$
\begin{aligned}
\eta_{u} & =-\frac{\nu_{i}}{u \bar{\nu}_{i}}<0, \quad \eta_{\omega}=\frac{\nu_{i}}{\omega \bar{\nu}_{i}}>0, \quad \eta_{\Delta_{i}}=\frac{\nu_{i}}{\Delta_{i} \beta \bar{\nu}_{i}}>0 \\
\eta_{\bar{\nu}_{i}} & =\frac{(1-\beta) \eta_{i}}{\beta}>0, \quad \eta_{\bar{c}_{i}}=\frac{1}{-\mu \frac{\Delta_{i}}{u} \beta(1-\beta) \frac{M}{\nu_{i}^{2}}}<0 \quad \eta_{\mu}=\frac{\nu_{i}}{\mu \beta}>0
\end{aligned}
$$

\subsection{Appendix 2: Proof of Proposition 2}

Proof of proposition 2:

$$
\begin{aligned}
& 0=F=\phi(E-u)-\mu M(\omega, u, \nu(\eta(u, \omega, \Delta, \mu, \bar{c}, \bar{\nu}))) \\
& 0=G=\Delta(\rho+\phi+\mu M(\omega, u, \nu(\eta(u, \omega, \Delta, \mu, \bar{c}, \bar{\nu}))) / u)-v+w-c(\nu(\eta(u, \omega, \mu, \bar{c}, \bar{\nu}))) \\
& 0=H=\omega-\frac{q}{p+q} \Omega+E-u
\end{aligned}
$$

$F, G, H$ have continuous partial derivatives with respect to all variables. As all variables are positive, and since $\frac{q}{p+q} \Omega-E>0 \rightarrow \omega>u$, the determinant of the Jacobian matrix for the smooth function $f(x, y)=(F, G, H)(x, y), y=$ $(u, \omega, \Delta), z=(\mu, \bar{c}, \bar{\nu}, q, p, \Omega, E, v, w)$ does not vanish 


$$
\begin{aligned}
|A| & =\left|\begin{array}{ccc}
-\mu \frac{M}{\omega} & -\phi & -\mu(1-\beta) \frac{M}{\Delta \beta} \\
\Delta \mu \beta \frac{m}{\omega} & -\Delta \mu \beta \frac{m}{u} & (\rho+\phi+\mu m) \\
1 & -1 & 0
\end{array}\right| \\
& =-\left[(\rho+\phi+\mu m)\left(\phi+\mu \frac{M}{\omega}\right)+\mu^{2}(1-\beta) M(\underbrace{\frac{m}{u}-\frac{m}{\omega}}_{>0})\right] \neq 0
\end{aligned}
$$

So that the Jacobian matrix is invertible and the implicit function theorem can be applied. System (7) impicitly defines the functions

$$
\begin{aligned}
u^{*} & =u^{*}(\mu, \bar{c}, \bar{\nu}, q, p, \Omega, E, v, w) \\
\omega^{*} & =\omega^{*}(\mu, \bar{c}, \bar{\nu}, q, p, \Omega, E, v, w) \\
\Delta^{*} & =\Delta^{*}(\mu, \bar{c}, \bar{\nu}, q, p, \Omega, E, v, w) .
\end{aligned}
$$

\subsection{Appendix 3 : Proof of Proposition 3}

Proof of proposition 3 :

$$
\begin{aligned}
& d a=(d \omega, d u, d \Delta)^{\prime}, \\
& A=\left(\begin{array}{ccc}
-\mu \frac{M}{\omega} & -\phi & -\mu(1-\beta) \frac{M}{\Delta \beta} \\
\Delta \mu \beta \frac{m}{\omega} & -\Delta \mu \beta \frac{m}{u} & (\rho+\phi+\mu m) \\
1 & -1 & 0
\end{array}\right) \\
& d B=\left(\begin{array}{c}
\frac{M}{\beta} d \mu-\frac{\nu u}{\Delta \beta} d \bar{c}+\mu \frac{(1-\beta)^{2}}{\beta} M d \bar{\nu} \\
0 \\
0
\end{array}\right) \\
& \frac{d u}{d \bar{c}}=\frac{-(\rho+\phi+\mu m) \frac{\nu u}{\Delta \beta}}{\mu^{2} M(1-\beta) m\left(\frac{1}{\omega}-\frac{1}{u}\right)-(\rho+\phi+\mu m)\left(\mu \frac{M}{\omega}+\phi\right)}>0 \\
& \frac{d u}{d \bar{\nu}}=\frac{(\rho+\phi+\mu m) \mu \frac{(1-\beta)^{2}}{\beta} M}{\mu^{2} M(1-\beta) m\left(\frac{1}{\omega}-\frac{1}{u}\right)-(\rho+\phi+\mu m)\left(\mu \frac{M}{\omega}+\phi\right)}<0
\end{aligned}
$$

\subsection{Appendix 4: Proof of Proposition 4}

Proof of propostition 4:

$$
\begin{aligned}
d a & =(d \omega, d u, d \Delta)^{\prime}, \\
A & =\left(\begin{array}{ccc}
-\mu \frac{M}{\omega} & -\phi & -\mu(1-\beta) \frac{M}{\Delta \beta} \\
\Delta \mu \beta \frac{m}{\omega} & -\Delta \mu \beta \frac{m}{u} & (\rho+\phi+\mu m) \\
1 & -1 & 0
\end{array}\right) \\
d B & =\left(\begin{array}{c}
0 \\
d v-d w \\
0
\end{array}\right)
\end{aligned}
$$




$$
\begin{aligned}
& \frac{d u}{d v}=\frac{\mu(1-\beta) \frac{M}{\Delta \beta}}{\mu^{2} M(1-\beta) m\left(\frac{1}{\omega}-\frac{1}{u}\right)-(\rho+\phi+\mu m)\left(\mu \frac{M}{\omega}+\phi\right)}<0 \\
& \frac{d u}{d w}=\frac{-\mu(1-\beta) \frac{M}{\Delta \beta}}{\mu^{2} M(1-\beta) m\left(\frac{1}{\omega}-\frac{1}{u}\right)-(\rho+\phi+\mu m)\left(\mu \frac{M}{\omega}+\phi\right)}>0
\end{aligned}
$$

\section{References}

[1] Acs, Z.J., Desai, S. and Hessels, J. (2008). 'Entrepreneurship, economic development and institutions', Small Business Economics, 31: 219-234.

[2] Acs, Z.J. and Storey, D. (2004). 'Introduction: Entrepreneurship and Economic Development', Regional Studies, 38 (8): 871-877.

[3] Acs, Z.J. and Szerb, L. (2007). 'Entrepreneurship, Economic Growth and Public Policy', Small Business Economics, 28:109-122.

[4] Antoncic, B. and Hisrich, R.D. (2001). 'Intrapreneurship: Construct Refinement and Cross-Cultural Validation', Journal of Business Venturing, 16(5): 495-527.

[5] Audretsch, D.B. (2007). 'Entrepreneurship Capital and Economic Growth', Oxford Review of Economic Policy, 23: 63-78.

[6] Audretsch, D.B. and Keilbach, M.C. (2004). Entrepreneurship Capital and Economic Performance', Regional Studies, 38 (8): 949-959.

[7] Audretsch, D.B., Keilbach, M.C. and Lehmann, E.E. (2006). Entrepreneurship and Economic Growth. Oxford: Oxford University Press.

[8] Alkire, S. (2002). Valuing Freedoms: Sen's Capability Approach and Poverty Reduction. Oxford: Oxford University Press.

[9] Alkire, S. (2005). 'Capability and Functionings: Definition and Justification', Human Development and Capability Association Briefing Note, September.

[10] Alkire, S. (2009).'Conceptual Overview of Human Development: Definitions, Critiques, and Related Concepts', Background Paper for the 2010 Human Development Report. OPHI, November,

[11] Alkire, S. and Foster, J. (2008).'Counting and Multidimensional Poverty Measurement', OPHI Working Paper Series, January. 
[12] Anand, P., Hunter, G., Carter, I., Dowding, K., Guala, F. and Van Hees, M. (2009). 'The Development of Capability Indicators', Journal of Human Development and Capabilities, 10 (1): 125-152.

[13] Banerjee, A.V. and Duflo, E. (2007). 'The Economic Lives of the Poor', Journal of Economic Perspectives, 21 (1): 141-67.

[14] Baumol, W.J. (1990). 'Entrepreneurship: Productive, Unproductive and Destructive', The Journal of Political Economy, 98(5): 893-921.

[15] Blanchflower, D.G., Oswald, A.J. and Stutzer, A. (2001). 'Latent Entrepreneurship Across Nations', European Economic Review, 45: 680-91.

[16] Casson, M. (2003). The Entrepreneur: An Economic Theory. 2nd ed. Cheltenham: Edward Elgar.

[17] Clark, D.A. (2005). 'The Capability Approach: Its Development, Critiques and Recent Advances', Global Poverty Research Group Working Paper WPS-032. University of Manchester.

[18] Coyne, C.J. and Leeson, D.T. (2004). 'The Plight of Underdeveloped Countries', Cato Journal, 24(3): 235-49.

[19] Davidsson, P. (2004). Researching Entrepreneurship. New York: Springer.

[20] Estrin, S., Meyer, K.E. and Bytchkova, M. (2006). 'Entrepreneurship in Transition Economies', in Casson, M., Yeung, B., Basu A. and Wadeson, N. (eds) The Oxford Handbook of Entrepreneurship. Oxford: Oxford University Press: 693-725.

[21] Fonseca, R., Michaud, P-C. and Sopraseuth, T. (2007). 'Entrepreneurship, Wealth, Liquidity Constraints, and Start-Up Costs', Comparative Labor Law and Policy Journal, 28: 637-74.

[22] Giannetti, M. and Simonov, A. (2004). 'On the Determinants of Entrepreneurial Activity: Social Norms, Economic Environment and Individual Characteristics', Swedish Economic Policy Review, 11: 269-313.

[23] Gifford, S. (1998). 'Limited Entrepreneurial Attention and Economic Development', Small Business Economics, 10: 17-30.

[24] Gollin, D. (2008). 'Nobody's business but my own: Self-employment and small enterprise in economic development', Journal of Monetary Economics, 55 (2) : 219-233.

[25] Grégoire, D. and Shepherd, D.A. (2005). 'What Makes Opportunities More or Less Obvious? Findings From an Experiment with Entrepreneurs', Babson College Entrepreneurship Research Conference (BCERC) 2005. Available at SSRN: http://ssrn.com/abstract=1499379

[26] Gries, T. and Naudé, W.A.(2010).'Entrepreneurship and Structural Economic Transformation', Small Business Economics Journal, 34 (1):13-29. 
[27] Hamilton, B.A. (2000). 'Does Entrepreneurship Pay? An Empirical Analysis of the Returns to Self-Employment', Journal of Political Economy, 108(3): 604-31.

[28] Hart, D.M. (2003). 'Entrepreneurship Policy: What it is and Where it came from', in Hart, D.M. (ed.) The Emergence of Entrepreneurship Policy: Governance, Start-ups and Growth in the U.S. Knowledge Economy. Cambridge: Cambridge University Press: 3-19.

[29] Hitt, M.A., Ireland, R.D., Camp, S.M. and Sexton, D.L. (2001). 'Entrepreneurial Strategies for Wealth Creation', Strategic Management Journal, 22: 479-91.

[30] Kirzner, I.M. (1973). Competition and Entrepreneurship. Chicago: University of Chicago Press.

[31] Licht, A.N. (2007). 'The Entrepreneurial Spirit and What the Law Can Do About It', Comparative Labor Law and Policy Journal, 28: 817-62.

[32] McMullen, J.S., Plummer, L.A. and Acs, Z.J. (2007). 'What is an Entrepreneurial Opportunity?', Max Planck Institute Discussion Papers on Entrepreneurship, Growth and Public Policy 100\%. Jena: Max Planck Institute of Economics.

[33] Mehlum, H., Moene, K., Torvik, R. (2003). 'Predator or Prey? Parasitic Enterprises in Economic Development', European Economic Review, 47: 275-94.

[34] Minniti, M. (2008). 'The Role of Government Policy on Entrepreneurial Activity: Productive, Unproductive, or Destructive?', Entrepreneurship Theory and Policy, September, 779-790.

[35] Minniti, M. and Naudé, W.A. (2010). 'What do We Know About the Patterns and Determinants of Female Entrepreneurship Across Countries?', The European Journal of Development Research, 22 (2). 1-17.

[36] Moskowitz, T.J. and Vissing-Jorgensen. A. (2002). 'The Returns to Entrepreneurial Investment: A Private Equity Premium Puzzle?', American Economic Review, 92: 745-79.

[37] Murphy, K., Schleifer, A. and Vishny, R. (1991). 'The Allocation of Talent: Implications for Growth', Quarterly Journal of Economics, 106(2): 503-30.

[38] Naudé, W.A. (2009). Entrepreneurship is not a Binding Constraint on Growth and Development in the Poorest Countries' WIDER Research Paper RP2009/45, United Nations University, Helsinki, Finland.

[39] Naudé, W.A. (2010a). 'Entrepreneurship, Developing Countries and Development Economics: New Approaches and Insights', Small Business Economics Journal, 34 (1): 
[40] Naudé, W.A. (2010b). Entrepreneurship and Economic Development. Basingstoke: Palgrave Macmillan (forthcoming).

[41] Pissarides, C. A. (2000), Equilibrium unemployment theory 2nd ed.: MIT Press.

[42] Robeyns, I. (2003). 'The Capability Approach: An Interdisciplinary Introduction. Mimeo: Amsterdam School of Social Sciences, Dec.

[43] Robeyns, I. (2005). 'The Capabilities Approach: A Theoretical Survey', Journal of Human Development, 6 (1): 93-114.

[44] Schumpeter, J.A. (1934). The Theory of Economic Development. Cambridge MA: Harvard University.

[45] Shane, S. and Venkataraman, S. (2000). 'The Promise of Entrepreneurship as a Field of Research', Academy of Management Review, 25(1): 217-26.

[46] Shane, S. (2000). 'Prior Knowledge and the Discovery of Entrepreneurial Opportunities', Organizational Science, 11 (4): 448-469.

[47] Sen, A. (1985). Commodities and Capabilities. North-Holland: Amsterdam.

[48] Sen, A. (2000). Development as Freedom. New York: Anchor Books.

[49] Teschl, M. and Comim, F. (2005). 'Adaptive Preferences and Capabilities: Some Preliminary Conceptual Explorations', Review of Social Economy, 63 (2): $229-247$

[50] UNDP (1996). Human Development Report. United Nations Development Programme. New York. 